\title{
Kinerja Aparatur Sipil Negara Badan Pengembangan Sumber Daya Manusia Daerah Provinsi Sulawesi Utara Dalam Pelayanan Publik
}

\author{
Paulus Tamaka \\ Badan Pengembangan Sumber Daya Manusia Daerah \\ Provinsi Sulawesi Utara \\ JL. Raya Walanda Maramis KM.10 Watutumou - Manado 95122 \\ Email : paulustamaka@yahoo.com
}

Received: 02 Oktober 2020; Revised: 21 November 2020; Accepted: 28 Desember 2020
DOI: $\underline{\text { http://dx.doi.org/10.37905/aksara.7.1.111-122.2021 }}$

\begin{abstract}
Abstrak
Prestasi Kinerja adalah merupakan hasil kerja yang telah dicapai oleh seseorang pegawai dalam menjalankan tugas dan fungsinya. Kinerja dapat menjadi sebuah ukuran keberhasilan suatu perangkat daerah atau instansi dalam menjalankan tugas dan fungsinya. Untuk itu perlu dilakukan penilaian kinerja aparatur, penilaian ini dimaksudkan untuk melihat apakah hasil kerja dari aparatur sudah sesuai dengan apa yang diharapkan. Salah satu masalah yang terjadi di Badan Pengembangan Sumber Daya Manusia Daerah yaitu Lambatnya pelayanan yang diberikan aparatur, salah satu penyebabnya yaitu yang terkadang tidak mengikuti prosedur pelayanan yang telah ditetapkan, seperti tidak memenuhi persyaratan yang lengkap, dan terkadang ada beberapa pelayanan surat yang diperlukan tanda tangan dari Kepala Badan sehingga pada saat Kepala Badan tidak ada ditempat suatu urusan tersebut harus menunggu tanda tangan Kepala Badan sehingga pelayanan sedikit lambat serta masalah yang lainnya karena tidak ada pendelegasian.

Adapun Tujuan penelitian ini adalah untuk mengetahui dan mendeskripsikan Kinerja Aparatur Sipil Negara Dalam Pelayanan Publik di Badan Pengembangan Sumber Daya Manusia Daerah. Untuk mencapai tujuan tersebut metode yang digunakan dalam penelitian ini adalah kulitatif. Jenis penelitian ini adalah penelitian deskriptif kualitatif. Pengumpulan data dilakukan dengan melalui wawancara, observasi dan dokumentasi. Sumber data yang digunakan berasal dari data primer dan sekunder.

Dalam penelitian ini diperoleh kesimpulan bahwa kinerja Aparatur sipil negara dalam Pelayanan Publik secara umum dapat dikatakan baik dan sedang menuju pada level yang lebih baik lagi. Berdasarkan indikator kinerja yang digunakan dapat dikatakan bahwa kinerja Aparatur Sipil Negara sudah cukup baik. Namun sedikit banyaknya aparatur harus lebih membenahi dan lebih meningkatkan lagi kinerjanya dalam pelayanan publik.
\end{abstract}

Kata Kunci : Kinerja, Aparatur, Pelayanan 


\begin{abstract}
Performance achievement is the result of work that has been achieved by an employee in carrying out their duties and functions. Performance can be a measure of the success of a regional apparatus or agency in carrying out its duties and functions. For this reason, it is necessary to carry out an apparatus performance appraisal, this assessment is intended to see whether the work results of the apparatus are in accordance with what is expected. One of the problems that occurs in the Regional Human Resources Development Agency is the slow service provided by the apparatus, one of the causes is that sometimes they do not follow the service procedures that have been set, such as not meeting complete requirements, and sometimes there are several letter services that require signature from the Head of the Agency so that when the Head of the Agency is not at the place of an affair, he must wait for the signature of the Head of the Agency so that the service is a little slow and other problems are due to no delegation.

The purpose of this study was to determine and describe the performance of the State Civil Apparatus in Public Service at the Regional Human Resources Development Agency. To achieve this goal, the method used in this research is qualitative. This type of research is a qualitative descriptive study. Data collection was carried out through interviews, observation and documentation. The data sources used are primary and secondary data.

In this study, the conclusion is that the performance of the state civil apparatus in public services is generally good and is heading to a better level. Based on the performance indicators used, it can be said that the performance of the State Civil Apparatus is quite good. However, more or less the apparatus must improve and further improve their performance in public services.
\end{abstract}

Keywords : Performance, Apparatus, Service

\title{
PENDAHULUAN
}

Dalam Undang -undang Nomor 5 Tahun 2014 tentang Aparatur Sipil Negara yang selanjutnya disingkat ASN adalah profesi bagi Pegawai Negeri Sipil dan pegawai pemerintah dengan perjanjian kerja yang bekerja pada instansi pemerintahan. Pegawai Aparatur Sipil Negara terdiri dari Pegawai Negeri Sipil (PNS) dan Pegawai Pemerintah dengan Perjanjian Kerja (PPPK) yang diangkat oleh pejabat pembina kepegawaian dan diserahi tugas dalam suatu jabatan pemerintahan atau diserahi tugas negara lainnya dan digaji berdasarkan peraturan perundang-undangan. Aparatur Sipil Negara berperan sebagai perencana dan pengawas penyelenggaraan tugas umum pemerintahan dan pembangunan nasional melalui pelaksanaan kebijakan dan pelayanan publik profesional bebas dari intervensi politik, serta bersih dari KKN (Korusi Kolusi dan Nepotisme). Sesuai dengan perannya, Aparatur Sipil Negara harus memberikan hasil kerja (kinerja) yang baik dalam perannya sebagai perencana dan pengawas penyelenggaraan tugas umum pemerintahan dan pembangunan nasional melalui pelaksanaan kebijakan dan pelayanan publik yang profesional. 
Sebagai Aparatur pemerintahan ASN mempunyai salah satu peran yang penting dalam tugas dan fungsinya sebagai Aparatur Sipil Negara dalam penyelenggaraan tugas pemerintahan dan pembangunan nasional melalui pelaksanaan pelayanan publik kepada masyarakat. Aparatur Sipil Negara melakukan perannya sebagai aparatur pemerintah dengan memberi pelayanan publik. Aparatur Sipil Negara yang memberikan pelayanan publik kepada masyarakat adalah Aparatur Sipil Negara yang ditempatkan diinstansi pemerintahan yang ada, salah satunya seperti di Badan Pengembangan Sumber Daya Manusia Daerah. Pelayanan publik yang diberikan Aparatur Sipil Negara salah satunya adalah pelayanan administrasi. Pelayanan administrasi yang diberikan oleh Aparatur Sipil Negara yang ada di Badan Pengembangan Sumber Daya Manusia Daerah salah satunya adalah berupa pelayanan administrasi seperti pengurusan penyelenggaraan pelatihan. Dalam perannya Aparatur Sipil Negara sebagai perencana, pengawas dan penyelenggara pemerintahan umum melalui pelaksanaan pelayanan publik. Aparatur Sipil Negara BPSDMD dituntut memberikan hasil kerja (kinerja) yang baik dalam melaksanakan tugas dan memberikan pelayanan publik seperti pelayanan administrasi yang diberikan kepada masyarakat yang datang. Sejatinya Aparatur Sipil Negara merupakan penyelenggara pelayanan publik. Aparatur Sipil Negara dituntut untuk memberikan kinerja dengan produktivitas yang baik dalam memberikan pelayanan, memberikan kualitas pelayanan yang baik dan prima, dimana Aparatur Sipil Negara responsive serta responsibel dalam melakasanakan dan memberikan pelayanan publik kepada masyarakat dan bertanggung jawab atau ada pertanggung jawaban (akuntabel) terhadap tugas dan fungsinya serta hasil pencapaian yang telah dilaksanakannya. Berdasarkan observasi awal penulis pada Badan Pengembangan Sumber Daya Manusia Daerah ditemukan beberapa hal yaitu, dalam pelaksanaan pelayanan publik, cendrung cukup lambat dalam (1) Kemampuan Sumber Daya Manusia berbeda-beda, (2) Tanggungjawab melaksanakan tugas bervariasi (3) Kemampuan memecahkan masalah terbatas memberikan pelayanan kepada masyarakat. Terkadang satu urusan administrasi saja seperti suratsurat diselesaikan dengan tempo waktu yang cukup lama dimana, suatu urusan tersebut seharusnya dapat diselesaikan dalam kurun waktu 60 hingga 120 menit saja, terkadang menjadi lebih lama waktu akan selesai dari urusan tersebut.

Kemudian dari akuntabilitas dan pertanggung jawabanya kinerja Aparatur Sipil Negara masih belum terlihat, karena saat yang seharusnya mereka memberikan pelayanan mereka seakan melemparkan tugas tersebut kepada pegawai lain untuk mengerjakan pekerjaan tersebut dan tidak bertanggung jawab terhadap apa yang menjadi tugas dan fungsinya terhadap masyarakat dalam memberikan pelayanan meski hal ini tak sering kali dilakukan oleh aparatur. Dari keterbukaan terhadap masyarakat, sudah cukup terbuka tetapi terkadang beberapa dari masyarakat kurang memanfaatkan dan berpartisipasi pada ruang publik yang disediakan padahal dengan berpartisipasi dalam setiap sosialisasi atau ruang publik, dapat berdampak positif bagi kinerja aparatur dan rencana ke depan.

Berdasarkan latar belakang masalah yang ada, maka penulis tertarik untuk mengetahui lebih lanjut dan melakukan penelitian berjudul "Kinerja Aparatur Sipil Negara Badan Pengembangan Sumber Daya Manusia Daerah dalam Pelayanan Publik". 


\section{METODE}

Jenis penelitian yang digunakan dalam penelitian ini adalah penelitian deskriptif kualitatif. Fokus Penelitian ini adalah berdasarkan indikator yang digunakan untuk mengukur kinerja adalah Produktivitas, Kualitas Pelayanan, Resposivitas, Responsibilitas, Akuntabilitas serta faktor pendukung dan penghambat kinerja Aparatur Sipil Negara dalam Pelayanan publik di Badan Pengembangan Sumber Daya Manusia Daerah.

Jenis data yang digunakan dalam penelitian ini meliputi data primer dan data sekunder. Dalam penelitian ini penulis menggunakan 2 teknik pengambilan data yaitu purposive dan accidental (aksidental) sampling, dimana Kepala Badan sebagai key informan, Sekretaris Badan sebagai informan, para Kepala Sub Bagian sebagai informan, dan staf Badan sebagai informan, serta masyarakat yang memperoleh pelayanan sebagai informan.

Teknik Pengumpulan Data

Teknik Pengumpulan data yang digunakan dalam penelitian ini adalah sebagai berikut:

a. Penelitian Kepustakaan

b. Penelitian Lapangan

\section{Teknik Analisis Data}

a. PengumpulanData

b. Penyederhanaan Data

c. Penyajian Data

d. Penarikan Kesimpulan

\section{KAJIAN PUSTAKA \\ Pengertian dan Indikator Kinerja}

Menurut Amstrong (1998:7) sebelumnya berpandangan bahwa manajemen kinerja adalah pendekatan strategis dan terpadu untuk menyampaikan sukses berkelanjutan pada organisasi dengan memperbaiki kinerja karyawan yang bekerja di dalamnya dan dengan meengembangkan kapabilitas tim dan didalamnya dan dengan mengembangkan kapabilitas tim dan kontributor individu.

Sementara itu, Schwartz (1999:vii) memandang manajemen kinerja sebagai gaya manajemen yang dasarnya adalah komunikasi terbuka antara manajer dan karyawan yang menyangkut penetapan tujuan, memberikan umpan balik baik dari manajer kepada karyawan maupun sebaliknya dari karyawan kepada manajer, demikian pula penilaian kinerja. Disini tampak bahwa Schwartz melihat manajemen kinerja hanya sebagai salah satu gaya manajemen, namun dari sisi subtansinya mirip dengan pandangan Bacal sebagai suatu proses komunikasi.

Indikator kinerja atau performance indicators kadang-kadang dipergunakan secara bergantian dengan ukuran kinerja, tetapi banyak pula yang membedakannya Pengukuran

AKSARA: Jurnal IImu Pendidikan Nonformal 
kinerja berkaitan dengan hasil yang dapat dikuantitatifkan dan mengusahakan data setelah kejadian. Namun kinerja memerlukan adanya dukungan digambarkan oleh Hersey, Blanchard, dan Johnson dengan penjelasan seperti berikut:

1. Tujuan

Tujuan merupakan keadaan yang berbeda yang secara aktif dicari oleh seorang individu atau organisasi untuk dicapai. Pengertian tersebut mengandung makna bahwa tujuan bukanlah merupakan persyaratan, juga bukan merupakan sebuah keinginan.

Tujuan bukan merupakan sesuatu keadaan yang lebih baik yang ingin dicapai dimasa yang akan datang. Dengan demikian, tujuan menunjukkan arah tersebut, dilakukan kinerja untuk mencapai tujuan. Untuk mencapai tujuan, diperlukan kinerja individu, kelompok, dan organisasi. Kinerja individu maupun organisasi berhasil apabila dapat mencapai tujuan yang diinginkan.

2. Standar

Standar mempunyai arti penting karena memberitahukan kapan suatu tujuan dapat diselesaikan. Standar merupakan suatu ukuran apakah tujuan yang diinginkan dapat dicapai.

Tanpa standar, tidak dapat diketahui kapan suatu tujuan tercapai.

Standar menjawab pertanyaan tentang kapan kita tahu bahwa kita sukses atau gagal. Kinerja seseorang dikatakan berhasil apabila mampu mencapai standar yang ditentukan atau disepakati bersama antara atasan dan bawahan.

3. Umpan Balik

Antara tujuan, standar, dan umpan balik bersifat saling terkait. Umpan balik melaporkan kemajuan, baik kualitas maupun kuantitas, dalam mencapai tujuan yang didefenisikan oleh standar. Umpan balik terutama penting ketika kita mempertimbangkan "real goals" atau tujuam sebenarnya. Tujuan yang dapat diterima oleh pekerja adalah tujuan yang bermakna dan berharga.

Umpan balik merupakan masukan yang dipergunakan untuk mengukur kemajuan kinerja, standar kinerja, dan pencapaian tujuan. Dengan umpan balik dilakukan evaluasi terhadap kinerja dan sebagai hasilnya dapat dilakukan perbaikankinerja.

4. Alat Sarana

5. Kompetensi

6. Motif

7. Peluang

Pengertian Pelayanan Publik

Boediono (2003:60) pelayanan merupakan suatu proses bantuan kepada orang lain dengan cara-cara tertentu yang memerlukan kepekaan dan hubungan interpersonal agar terciptanya kepuasan dan keberhasilan. Dalam keputusan Menteri Pendayagunaan Aparatur Negara Nomor 63 tahun 2003, pelayanan publik adalah segala kegiatan pelayanan yang dilaksanakan oleh penyelenggara pelayanan publik sebagai upaya pemenuhan kebutuhan penerima pelayanan maupun pelaksana ketentuan peraturanperundang-undangan. 
Prinsip-prinsip Pelayanan Publik

Penyelengaraan pelayanan publik juga harus memenuhi beberapa prinsip pelayanan sebagaimana yang disebutkan dalam Keputusan Menteri Pendayagunaan Negara Nomor 63 Tahun 2003 adalah sebagai berikut :

1. Kesederhanaan

2. Kejelasan

3. Kepastianwaktu

4. Akurasi

5. Keamanan

6. Tanggungjawab

7. Kelengkapan sarana danprasarana

8. Kemudahanakses

9. Kedisiplinan, kesopanan, dankeramahan

10. Kenyamanan

Kualitas Pelayanan publik

Untuk mencapai kepuasan dituntut kualitas pelayanan prima yang tercermin dari Sinambella (2008:6) adalah sebagai berikut :

2. Transparansi

3. Akuntabilitas

4. Kondisonal

5. Partisipatif

6. Kesamaanhak

7. Keseimbangan hak dan kewajiban

\section{HASIL PENELITIAN}

Gambaran Obyek Penelitian

Badan Pengembangan Sumber Daya Manusia Daerah Provinsi Sulawesi Utara, merupakan perangkat daerah pelayanan pengembangan kompetensi sumber daya manusia khususnya Aparatur Sipil Negara yang diharapkan berkualitas untuk mewujudkan penyelenggaraan pemerintahan yang berhasil guna dan berdaya guna.

Jumlah Aparatur Sipil Negara di kantor Badan Pengembangan Sumber Daya Manusia Daerah

Aparatur Sipil Negara yang bekerja berjumlah 104 orang diantaranya aparatur ASN berjumlah 69 orang dan Aparatur THL 35 orang. Dari hasil survei penulis dari jumlah aparatur sipil Negara yang bekerja di Badan Pengembangan Sumber Daya Manusia Daerah berjumlah 104 orang baik jenis kelamin aparatur laki-laki dan aparatur perempuan.

Fasilitas Kantor Badan Pengembangan Sumber Daya Manusia Daerah

Fasilitas yang tersedia sudah cukup memadai bagi aparatur. Tetapi perangkat Komputer masih dapat dikatakan kurang karena dibidang - bidang hanya tersedia unit saja. Hal ini dapat menjadi masalah serius untuk kedepannya. Jika tidak melengkapi 
fasilitas sesuai dengan jumlah aparatur dan staf yang ada, hal ini akan menghambat kerja aparatur, dan Aplikasi tidak dapat dimaksimalkan fungsinya.

\section{Kinerja Aparatur Sipil Negara dalam Pelayanan Publik Produktivitas}

Menurut Dwiyanto dalam Pasolong (2007:178) produktivitas yaitu tidak hanya mengukur tigkat efisiensi tetapi juga mengukur efektivitas pelayanan.pada pelaksanaan pelayanan administrasi aparatur sipil negara mengggunakan aplikasi pelayanan berbasis teknologi yang dimaksudkan agar pelayanan dapat berlangsung efektif serta efisien. Dengan menggunakan aplikasi tersebut pelayanan dapat dilakukan dengan cepat dan dapat mempermudah aparatur dalam memberikan pelayanan.

\section{Kualitas Pelayanan}

Kualitas pelayanan adalah ukuran citra yang diakui masyarakat mengenai pelayanan yang diberikan yaitu masyarakat puas atau tidak puas. Menurut Dwiyanto dalam Pasolong (2007:178) banyak pandangan negatif terbentuk mengenai organisasi publik muncul karena ketidakpuasan publik terhadap kualitas pelayanan. Hingga saat ini belum ditemukan keluhan dari masyarakat tentang kualitas pelayanan yang diberikan. Sebagai salah satu upaya peningkatan kualitas dalam pelayanan di kantor Badan Pengembangan Sumber Daya Manusia Daerah aparatur menggunakan aplikasi pelayanan berbasis ilmu teknologi agar pelayanan dapat berlangsung dengan cepat dan efektif serta efisien. Kotak saran sebagai sarana untuk mengutarakan kritik dan saran juga disediakan aparatur bagi masyarakat untuk menyampaikan aspirasinya.

\section{Responsivitas}

Menurut Dwiyanto dalam Pasolong (2007:178) responsivitas adalah ukuran kemampuan birokrasi untuk mengenali kebutuhan masyarakat untuk menysun agenda dan prioritas pelayanan, serta mengembangkan program-program pelayanan publik sesuai dengan kebutuhan dan aspirasi masyarakat. Pada pelaksanaan pelayanan apartur sedikit lambat dalam memberikan respon pada masyarakat, tetapi dilain sisi semua itu karena aparatur sedang disibukkan dalam proses pelayanan, tetapi disaat masyarakat datang dengan berkas yang lengkap untuk mengurus, aparatur berusaha memberikan pelayanan yang baik, sebagai upaya mereka untuk memberikan pelayanan yang baik yang diinginkan oleh masyarakat, aparatur menggunakan aplikasi dalam pelayanannya agar pelayanan dapat menjadi lebih prima.

\section{Responsibilitas}

Menurut Dwiyanto dalam Pasolong (2007:178) responsibilitas adalah pelaksanaan kegiatan yang dilakukan harus sesuai dengan prinsip-prinsip administrasi yang benar dan kebijakan birokrasi baik eksplisit maupun implisit. Pada pelaksanaan pelayanan, aparatur dapat bekerja dengan disiplin waktu, sopan serta santun dalam melayani masyarakat dan berinterkasi dengan masyarakat dengan tutur kata yang baik serta dapat memberikan kenyamanan pada masyarakat serta menerapkan prinsip pelayanan lainnya. 
Akuntabilitas

Menurut Dwiyanto dalam Pasolong (2007:178-179) akuntabilitas publik digunakan untuk melihat seberapa besar kebijakan dan kegiatan birokrasi publik itu konsisten dengan kehendak publik. Dalam Undang-undang Nomor 5 tahun 2014 tentang Aparatur Sipil Negara disebutkan bahwa salah satu kewajiban dari Aparatur Sipil Negara adalah melaksanakan tugas dengan penuh pengabdian, kejujuran, kesadaran dan tanggung jawab. Sebagai bukti pertanggung jawaban aparatur dalam memberikan pelayanan yang baik serta memberikan kepuasan kepada masyarakat, aparatur sipil negara melakukan upaya untuk menaikkan kualitas pelayananya. Salah satunya yaitu menerapkan Aplikasi pelayanan administrasi berbasis ilmu tekhnologi dalam memberikan pelayanan pada masyarakat, dengan menggunakan Aplikasi tersebut pelayanan berlangsung lebih cepat dan dapat meningkatkan kualitas pelayanan terhadap masyarakat dengan aplikasi tersebut aparatur lebih mudah dan ringkas dalam melaksanakan pelayanan administrasi kepada masyarakat.

\section{Faktor Pendukung}

Menurut Pasolong (2007:188) Kompensasi adalah sesuatu yang diterima oleh pegawai sebagai balas jasa atas kinerja dan bermanfaat baginya. Kompensasi yang sesuai berdasarkan hasil yang dicapai aparatur dalam memberikan hasil kerja, akan menjadi stimulan bagi para aparatur untuk menunjukkan hasil kerja yang baik dan memuaskan, karena pencapaian hasil kerja dan prestasi yang baik akan diberikan penghargaan yang sesuai, berupa kompensasi atau bonus. Secara otomatis Aparatur akan mendapatkan gaji yang besar. Dengan diberikannya kompensasi sesuai dengan prestasi yang ada maka akan menjadikan aparatur lebih termotivasi untuk memberikan hasil kerja yang lebih baik lagi dari sebelumnya. Fasilitas yang lengkap seperti perangkat bertekhnologi juga akan mendukung hasil kerja yang baik bagi aparatur, terlebih lagi saat ini Badan Pengembangan Sumber Daya Manusia Daerah telah menggunakan Aplikasi pelayanan administrasi berbasis ilmu tekhnologi untuk memberikan pelayanan. Hal tersebut tentu menuntut agar Badan Pengembangan Sumber Daya Manusia Daerah menyediakan fasilitas berteknologi. Menurut Bill Creech (dalam Pasolong 2007:188) teknologi adalah lebih cendrung positif dan proaktif pegawai dalam melakukan pekerjaan, karena mereka memandang teknologi sebagai teman, bukan sebagai musuh untuk meningkatkan kinerja. Teknologi memungkinkan aparatur lebih kreatif merancang dan mengembangkan cara berfikir positif dalam strategi berbeda untuk lebih meningkatkan kinerja. Hal tersebut tentu memerlukan fasilitas pendukungnya seperti Komputer, karena jika fasilitas seperti komputer tidak lengkap dan kurang nantinya, akan membuat aplikasi pelayanan administrasi berbasis ilmu tekhnologi atau yang disingkat APIK tersebut akan menjadi penghambat dan memperlambat pelayanan, dan tentu saja dapat berimbas pada kinerja dalam pelayanan yang akan menurun.

Faktor Penghambat

Menurut Bill Creech (dalam Pasolong 2007:188) teknologi adalah lebih cendrung positif dan proaktif pegawai dalam melakukan pekerjaan, karena mereka memandang teknologi sebagai teman, bukan sebagai musuh untuk meningkatkan kinerja. Teknologi memungkinkan aparatur lebih kreatif merancang dan mengembangkan cara 
berfikir positif dalam strategi berbeda untuk lebih meningkatkan kinerja. Jadi perangkat berteknologi seperti komputer memiliki pengaruh besar dalam kinerja aparatur sipil negara dalam pelayanan. Jika fasilitas atau perangkat berteknologi tidak lengkap maka upaya yang dilakukan oleh aparatur untuk lebih meningkatkan kualitas pelayanan akan memberikan hasil yang buruk, karena saat ini Badan Pengembangan Sumber Daya Manusia Daerah menggunakan Aplikasi Pelayanan Administrasi berbasis ilmu tekhnologi, tentunya hal ini sangat membutuhkan fasilitas seperti perangkat komputer.

\section{PENUTUP}

1. Bahwa Kinerja aparatur dalam pelayanan dilihat dari efektivitas dan efisiensi sudah cukup baik, menggunakan aplikasi pelayanan berbasis teknologi menjadikan pelayanan di kantor Badan Pengembangan Sumber Daya Manusia Daerah dapat berlangsung cepat serta efektif dan efisien dan.

Kualitas pelyananan Aparatur cukup baik. Sebagai upaya aparatur dalam meningkatkan kualitas pelayanan, di kantor kelurahan menggunakan aplikasi pelayanan agar pelayanan dapat lebih berkualitas cepat serta efektif dan efisien. Keluhan serta krittikan dari masyarakat sampai saat ini belum ditemukan serta Responsivitas aparatur dalam memberikan pelayanan sudah cukup baik. Meski responnya sedikit lambat tetapi saat pelaksanaan pelayanan aparatur dapat memberikan kenyamanan pada masyarakat dengan memberikan pelayanan yang cepat, melayani dengan sopan dan santun.

2. Dari responsibilitas, aparatur dalam pelayanan cukup baik. Aparatur sudah melakukan tugas dan fungsinya dengan menerapkan prinsip-prinsip pelayanan dan Dari Akuntabilitas, dilihat dari keterbukaannya, Aparatur cukup terbuka dengan memberikan ruang publik bagi masyarakat untuk memberikan kritik atau sarannya secara langsung maupun tidak langsung melalui kotak saran. Dari pertanggung jawabannya cukup baik. karena aparatur meiliki tanggung jawab untuk memberikan pelayanan yang baik, mereka berupaya untuk menjadikan pelayanan lebih baik dengan menggunakan aplikasi pelayanan berteknologi.

3. Di Badan Pengembangan Sumber Daya Manusia Daerah yang menjadi faktor pendukung kinerja aparatur sipil negara adalah Fasilitas serta Kompensasi, dengan diberikan dua hal tersebut kinerja mereka dapat menjadi lebih baik dan Fasilitas yang kurang lengkap akan menjadi penghambat bagi aparatur, karena saat ini aparatur menggunakan aplikasi pelayanan berbasis ilmu teknologi jadi fasilitas yang lengkap seperti perangkat komputer sangat di butuhkan dalam prosesnya.

Saran

1. Untuk menjadikan produktivitas kerja pegawai semakin baik dan lebih baik lagi, sebaiknya fasilitas dan aplikasi seperti aplikasi yang digunakan sekarang di kantor Badan Pengembangan Sumber Daya Manusia Daerah lebih dikembangkan serta membuat terobosan yang lebih baik dari sebelumnya agar 
produktivitas aparatur semakin baik lagi sehingga pelayanan dapat lebih efisien lagi dan

Agar kualitas pelayanan menjadi lebih baik dan semakin baik lagi, jika ada saran serta kritik dari masyarakat mengenai pelayanan yang diberikan, sebaiknya segera dilakukan dan terus mengevaluasi kegiatan yang telah dilakukan. Aplikasi berrbasis teknologi yang telah diterapkan saat ini terus dikembangkan dan dimaksimalkan penggunaanya untuk pelayanan yang lebihberkualitas serta

Responsivitas Aparatur sebaiknya lebih ditingkatkan lagi, karena dalam pelayanan kepada masyarakat aparatur harus cepat memberikan respon pelayanan kepada masyarakat yang datang agar dapat lebih cepat mengenali keinginan dari setiap masyarakat yang datang.

2. Menerapkan asas-asas serta prinsip pelayanan yang ada merupakan hal yang harus dilakukan oleh pemberi pelayanan publik, untuk itu aparatur harus selalu menerapkan asas-asas serta prinsip pelayanan yang ada untuk memberikan pelayanan administrasi kepada masyarakat untuk memberikan kepuasan pada masyarakat dan hasil kinerja yang lebih baik lagi dan Bersikap terbuka kepada masyarakat dan memberikan ruang pada masyarakat serta memberikan kesempatan kepada masyarakat untuk berpartisipasi dalam membuat kinerja Aparatur Sipil Negara dalam memberikan pelayanan adalah hal yang patut dilakukan agar dapat menjadikan kinerja pelayanan dapat lebih baik, untuk itu selalu terbuka kepada masyarakat untuk menyuarakan kritik dan sarannya sebagai bahan evaluasi aparatur.

3. Untuk mendukung kinerja aparatur agar menjadi lebih baik lagi, faktor pendukung seperti fasilitas sebaiknya ditambah dan dimaksimalkan penggunaanya serta tak lupa pula untuk senantiasa merawat fasilitas dan faktor pendukung kinerja agar tetap dapat dimaksimalkan penggunaanya dan Untuk menghindari penghambat aparatur sipil negara dalam memberikan pelayanan kepada masyarakat kelengkapan fasilitas yang mendukung kinerja aparatur sebaiknya dilengkapi dan dirawat agar fasilitas yang ada selalu dapat dimaksimalkan dalam pelayanan kepada masyarakat.

Daftar Pustaka

Adam Indrawijaya, P e rilaku Organization. Fourth Printing, ( Bandung: Sinar Baru Publisher, 1989)

Colquitt et.al. , Trust, Trustworthiness, and Trust Propensity: A Meta-Analytic Test of Their Unique Relationships With Risk Taking and Job Performance . ( Journal of Applied Psychology Vol. 92, No.4, 2007 )

Daft Richard, Management, (Ohio Thomson - South Western, 2003), p. 98.

Dian R Newman and Richard M. Hodgetts. Human Resource Management: A Custumer-Oriented Approach, (New Jersey: Prentic-Hall, Upper Saddle River, 1998)

Fred Luthans, Organizational Behavior translation Vivin Andhika Yuwono, Shekar Purwanti, Th. Arie P, and Winong Rosari. (Yogyakarta: Andi, 2006) 
Jiang Z . et.al. , " Total Reward Strategy: A Human Resources Management Strategy Going with the Trend of the Times ", International Journal of Business and Management. Vol. 4, No. 11. November, 2009

Pace R. Wayne and Don F. Faules, Organizational Communication: Strategies to improve Company Performance , (Bandung: Remaja Rosdakarya, 1998)

Samuel C. Certo \& S. Travis Certo, Modern Management, ( Pearson Prentice Hall , 2006 )

Stepen P. Robbins, Organizational Behavior. Indonesian Edition, ( Jakarta: Publisher PT Prenhallindo , 1996 )

Sugiyono, Statistics for Research, (Bandung: Alfa Beta, 2004)

U . Silalahi, The Study of Administration Science, Concept, Theory, and Dimensions, ( Bandung: Sinar Baru, 2002)

Wibowo, Performance Management, (Jakarta: Rajawali Pers, 2009)

Undang-undang Nomor 5 Tahun 2014 Tentang Aparatur Sipil Negara.

Undang-undang Nomor 25 Tahun 2009 tentang Pelayanan Publik.

Peraturan Pemerintah Nomor 11 Tahun 2017 tentang Manajamen Pegawai Negeri Sipil

Keputusan Menteri Pendayagunaan Aparatur Negara Nomor 63 Tahun 2003. 
Volume : 07

Nomor : 01

Bulan : Januari

Tahun : 2021

http://ejurnal.pps.ung.ac.id/index.php/AKSARA/index

122 AKSARA: Jurnal IImu Pendidikan Nonformal 